\title{
PRAÇAS E PARQUES DA MICRORREGIÃO 12 DE PRESIDENTE PRUDENTE/SP - ESTUDO DE CASO
}

Leandro César Mendes dos Santos; Yohran César Medeiros Turi; Yeda Ruiz Maria; Sibila Corral de Area Leao Honda

Universidade do Oeste Paulista - UNOESTE, Faculdade de Engenharias e Arquitetura e Urbanismo, Presidente Prudente, SP. E-mail: yeda rm@hotmail.com

\section{RESUMO}

O espaço público é compreendido como um conceito próprio do urbanismo. Entende-se como elemento importante na estrutura da cidade, não devendo ser negligenciado, pois exercem papéis tanto funcionais como de circulação urbana, sociais e culturais através do convívio público, como ambientais na conservação e requalificação ambiental. Indiscutivelmente as praças e parques, como elementos do espaço público, são estruturadores e cujas áreas ocupadas precisam ter relação direta à população urbana. Portanto buscar-se-á aprofundar os conhecimentos a respeito das áreas verdes urbanas, praças e parques urbanos da microrregião 12 do município de Presidente Prudente-SP. A metodologia será através de levantamento bibliográfico, de pesquisa documental e de levantamentos físico territoriais urbanísticos.

Palavras-chave: Praças e parques; Microrregião 12; Presidente Prudente - SP.

\section{SQUARE AND URBAN PARKS IN MICROREGION 12 IN THE CITY OF PRESIDENTE PRUDENTE - SP - CASE STUDY}

\begin{abstract}
The public space is understood as a proper concept of urbanism. It is understood as an important element in the city's structure that should not be overlooked because play both functional roles as urban, social and cultural movement through public interaction, and environmental conservation and environmental improvement. Arguably the squares and parks as public space elements are structuring and whose occupied areas must be directly related to the urban population. So will seek to deepen the knowledge about the urban green areas, squares and urban parks microregion 12 in the city of Presidente Prudente-SP. The methodology will be through literature, documentary research and urban territorial physical surveys.
\end{abstract}

Keywords: Square and Urban Parks; Microregion 12; Presidente Prudente - SP. 


\section{INTRODUÇÃO}

O espaço público, lugar de representação e de expressão coletiva da sociedade pela filosofia política, é compreendido por Borja (2002) como um conceito próprio do urbanismo que às vezes se confunde com espaços verdes, equipamentos ou sistema viário, por excelência, local de socialização.

Para Leite (2011) os principais atributos de um espaço público são aqueles relacionados com a vida pública, com urbanidade, possibilitando diversidade de situações e pessoas.

Entende-se como elemento importante na estrutura da cidade, não devendo ser negligenciado, pois exercem papéis tanto funcionais como de circulação urbana, sociais e culturais através do convívio público, como ambientais na conservação e requalificação ambiental. Caldeira (2007) enfatiza afirmando que o espaço público se caracteriza por excelência como espaço coletivo, lugar de manifestação, de culto e de ritos, propício à interação social.

Llardent (1982) conceitua espaços públicos como o conjunto de espaços urbanos ao ar livre destinados ao pedestre para o descanso, o passeio, a prática esportiva e, em geral, o recreio e entretenimento em sua hora de ócio, sendo quaisquer das distintas áreas verdes que formam o sistema de espaços livres, as zonas verdes, espaços verdes, áreas verdes, equipamento verde. É qualquer espaço livre no qual predominam as áreas plantadas de vegetação, correspondendo, em geral, o que se conhece como parques, jardins ou praças (LLARDENT, 1982).

Entretanto no atual contexto das novas propostas urbanas, o espaço da praça perdeu prestígio como espaço de sociabilidade, local de encontro e de lazer, mas destaca-se como espaço livre, espaço de circulação e área verde (CALDEIRA, 2007).

Indiscutivelmente as praças e parques, como elementos do espaço público, são estruturadores e cujas áreas ocupadas precisam ter relação direta à população urbana, assim como possibilita maior permeabilidade de solo nas cidades, diminuindo os problemas causados pelo escoamento superficial das águas de chuva.

Estes espaços podem exercer importante papel na identidade dos lugares, além de relevado papel social, e não apenas o benefício com função higiênica ou espaço físico no contexto das cidades (PIZZOL, 2005). Para tanto Caldeira (2007) pontua que em vários países, políticas urbanas destacam a questão da melhoria da qualidade de vida nas grandes cidades por meio do resgate de espaços públicos e coletivos, assim como de estruturas arquitetônicas degradadas.

Entretanto a questão do uso do solo costuma negligenciar a reserva de áreas para essa finalidade, com leis de zoneamento e uso do solo que pouco efetivamente estabelece proteção e/ou ampliação das áreas verdes públicas (CUNHA, 2003).

Como no Brasil o processo de urbanização normalmente acontece de forma não planejada ou inadequada, suas cidades têm dificuldade na implantação de áreas urbanas para formar um sistema de espaços livres públicos coeso e completo, que atenda de maneira ampla e coerente toda a cidade (MENNHE e COELHO, 2000).

Assim sendo, com base nestes conceitos apresentados, busca-se, por meio deste artigo aprofundar os conhecimentos a respeito das áreas verdes urbanas - praças e parques urbanos, na cidade de Presidente Prudente - SP, verificando-se, quais que sofreram alteração de uso, identificando seus atuais usos e ocupação, mais especificamente na microrregião 12.

A metodologia seguida foi baseada na investigação qualiquantitativa, utilizando-se de levantamento bibliográfico, de pesquisa documental, de levantamentos físico territoriais urbanísticos das áreas verdes urbanas.

\section{PRESIDENTE PRUDENTE - SP E A MICRORREGIÃO 12}

A microrregião analisada é composta 12 (doze) bairros: Jardim Aviação, Jardim Boa Vista, Vila Maristela, Vila Bonita, Vila Prudente, Vila Machadinho, Vila Cel. Goulart, Vila São Pedro, Vila 
Dúbus, Vila Lessa, Vila Marques, Bairro do Bosque e Vila Jesus. Nestes foram identificadas e analisadas 8 (oito) áreas verdes que se configuram como praças (figura 01).

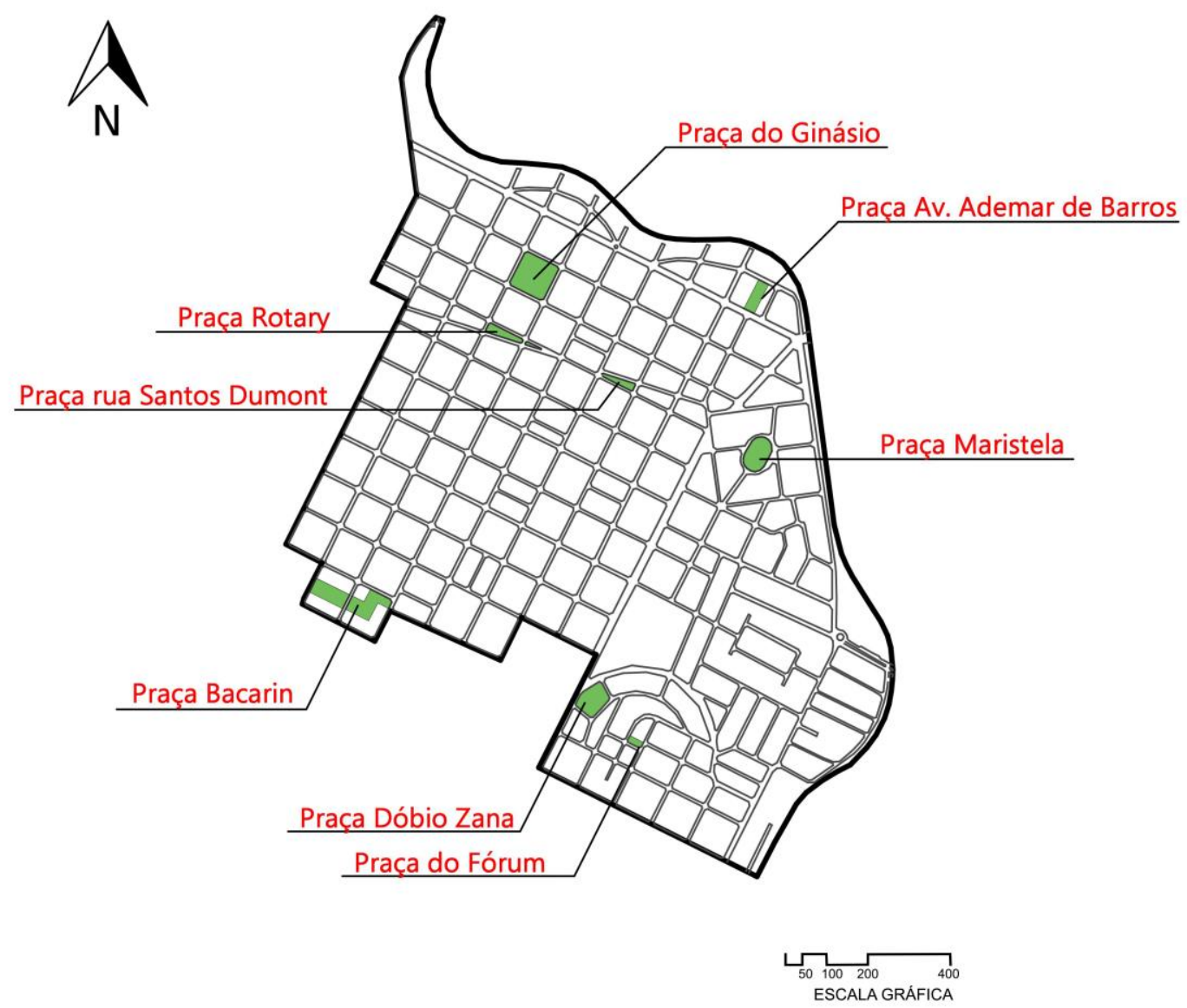

Figura 01. Localização das áreas verdes da Microrregião 12 Fonte: Autores, 2016.

Os mobiliários urbanos que estruturam as praças analisadas seguem o mesmo padrão de outras praças existentes na cidade: assentos, lixeiras, postes de iluminação, academia do idoso, pontos de ônibus, playground e telefone público. Entende-se não existir identidade do espaço praça com seu entorno imediato.

Praça do Fórum

A praça em questão oferece uma diversidade de uso considerável; localiza-se ao lado de um Fórum ${ }^{1}$, sendo ele um forte incentivador do fluxo intenso que ali ocorre, o estado de conservação é admissível, e apesar de pequena se faz assídua; assim, com a somatória de características que ali acontecem a praça é de valia para os usuários que por ali à percebem.

\section{Praça do Dóbio Zana}

Os mobiliários dessa praça são regulares e em parte chega a ser excessivos por não apresentar muito uso, quando há, se faz onde as árvores sombreiam. É possível identificar uso temporário do local por pessoas que esperam o ônibus, além de ser subutilizado como estacionamento e também por jovens que a procuram para andar de skate, reflexo da falta de estrutura de tal equipamento na região. Uma mobilização na internet propõe a construção de uma

\footnotetext{
${ }^{1}$ Local destinado à discussão pública.
} 
pista de skate sobre os espelhos d'água inutilizados nesta praça, assim, se aproximando mais da praça como lugar de prática esportiva.

Fato interessante é que esta praça é a única que apresenta um teatro ${ }^{2}$ ao ar livre, mas não é utilizado.

\section{Praça do Bacarin}

Como acontece em outras praças, esta costuma ser utilizada onde há sombras. É possível presenciar desde jovens até um público mais idoso frequentando o local. Há uso temporário por quem espera por ônibus, além de ser uma importante rota de circulação para pedestres do bairro que aproveitam da morfologia da praça passando entre as quadras para fazer de atalho para determinado destino.

Um fato que também pode ser presenciado foi a subutilização da quadra como depósito de materiais de construção, o que demonstra a negligência por parte da população em relação aos espaços públicos.

Praça Maristela

Nesta praça há uma igreja, fato esse que praticamente destina a praça à ser uma extensão da própria, assim ocorre ali convergência e interação social, assim propiciando que a praça em questão consiga valer de uma de suas muitas funções.

\section{Praça na Rua Santos Dumont}

O local pacato e deslocado das principais vias de fluxo que constituem o bairro fazem da praça um local pouco utilizado; de fato, a área é notado principalmente como lugar de embarque e desembarque de passageiros de transportes coletivos (ponto de ônibus), tal acontecimento ocorre em somatória de que a praça não oferece boa infraestrutura e atratividade aos usuários.

\section{Praça na Avenida Ademar de Barros}

Tal lugar tem como principal ocasionador de ação e fluxo um lanche de trailer permanente, localizado à frente da entrada principal; assim nota-se que mesmo o tal trailer não adentrando a praça, provoca uma situação de público - privado, pelo simples fato de apropriar-se de uma breve porção de área do lugar.

Porém, encontros e reuniões em praças públicas são benéficos, logo o limitado e acanhado uso do local pelo trailer acaba por forçar o uso da área. Uma segunda forma de utilização é o caminho que a praça oferece, sendo ela extensa, assim alcançando a rua posterior, servindo de passagem aos usuários, sendo o trajeto uma das muitas facetas que a praça deve exercer.

\section{Praça Rotarity}

Esta é a praça de uso mais escasso, isso muito ligado à falta de mobiliário urbano presente, quando há uso, este ocorre nas áreas sombreadas. Também foi presenciado a praça sendo utilizada como depósito de lixo.

\section{Praça Ginásio de Esportes}

Dentre todas esta é a que melhor demonstra o conceito de praça como lugar de socialização, convívio e lazer. É possível presenciar todos os tipos de usos por diferentes faixas etárias, desde jovens que frequentam o ginásio e as academias da praça, até idosos que vão se exercitar ou fazem da praça ponto de encontro.

O entorno constituído por uma igreja, mercado e creche contribui para que a praça seja um atrativo e consequentemente subutilizada por quem frequenta tais lugares, além do ginásio que se encontra junto à praça e da avenida Ademar de Barros, um importante eixo de circulação dentro da microrregião, assim, a praça se insere em um local importante dentro da estrutura da cidade.

\footnotetext{
${ }^{2}$ Arenas ovais ou circulares rodeadas de degraus a céu aberto típicas da Antiguidade.
} 


\section{CONSIDERAÇÕES FINAIS}

Dentre as praças analisadas há pontos nas quais diferem e outros que assemelham, nas praças de maior movimento como a do ginásio e da Maristela observa-se um mobiliário em melhor estado e mais opções para lazer, já onde não há tanto uso, o mobiliário se faz mal zelado.

O uso está muito associado à outras atividades ao redor desses espaços como igreja, ginásios, escolas, lanchonetes e ponto de ônibus, sendo menos frequente usuários em praças onde não tem tais atividades.

Quando há uso, este se faz principalmente onde há sombreamento durante o dia e iluminação à noite, no qual está relacionado ao conforto e segurança. Tais atributos são essenciais a serem tratados por parte do poder público, junto a isso, um maior zelo quanto aos mobiliários, muitos estando em estados de grande degradação, porém, como afirmado, parece haver falta de preocupação pela parte administrativa da cidade até por esse não haver uso, criando assim um ciclo vicioso.

\section{REFERENCIAS}

CREUS, Màrius Quintana. Espacios, muebles y elementos urbanos. In: serra, Josep. Elementos urbanos, mobiliário y microarquitectura. Barcelona: Gustavo Gili, p.6-14, 1996.

FERREIRA, A. L. de A.; MARQUES, S. Privado e público: inovação espacial ou social?. Revista Scripta Nova. N. 69. Barcelona, ago 2000 . Disponível em <http://www.ub.edu/geocrit/sn-69-20.htm>. Acesso em 5 ago, 2015

KOHLSDORF, Maria Elaine. A apreensão da Forma da Cidade. Brasília: Editora Universidade de Brasília, 1996.

LOBODA, C. R.; ANGELIS. B.L. D de. Áreas verdes públicas urbanas: conceitos, usos e funções. Revista Ambiência. Paraná, v.1 n.1 p. 125-139 jan./jun. 2005.

SOUSA, Rafael O.; OLIVEIRA, C. E. . A praça como lugar da diversidade cultural. In: IV Forúm de Educação e Diversidade, 2010, Tangará da Serra. Anais Iv Forum de Educação e Diversidade, 2010. 